\title{
Longitudinal changes in functional capacity among surviving old people continuously resident in hospitals and homes
}

\author{
L J DONALDSON
}

From the Department of Community Health, Leicester Royal Infirmary, PO Box 65, Leicester LE2 7LX, UK

SUMmaRY A group of surviving, continuously resident elderly people was identified through linkage of data from two cross sectional studies (three years apart) of all types of hospital and homes provided within a defined geographical area. Although 60-70\% were unchanged in their ability to perform basic activities of daily living, any change was most often deterioration: between three and four to one. The exception was for faecal incontinence: a higher proportion remained unchanged but of those who changed, more deteriorated than was so for other activities. Changeo was greater when all aspects of functional capacity were considered, though the extent of deterioration was similar. Greater change and greater deterioration were associated with: increasing age, the male sex, shorter initial duration of stay, and residence in a geriatric ward. After adjustment for differences in such factors, patients in geriatric and psychiatric wards deteriorated to a similar extent but significantly more than residents of homes for the elderly. Few such data are available, yet they are necessary for assessing the impact of different institutional regimens and formulating rehabilitation strategies.

Although longitudinal studies of the elderly which have focused on the effect of aging on such factors as intellectual function or behaviour and social adaptation have been carried out, data about changes in the functional status of elderly people are relatively scant.

Better decisions could be made regarding care for the elderly if data were available describing the impact of change on health or level of function.

The present study has examined changes in functional capacity among surviving elderly people in the entire range of institutionally based care provided within a defined geographical area.

\section{Methods}

The study was carried out in the Leicestershire Health District, a mixed urban and rural community with a total population of 836300 , of whom 112500 were aged 65 and over. This proportion of elderly people was similar to that in the population of Britain as a whole.

In Leicestershire, as in other parts of Britain, institutional care for the elderly is provided by three main agencies: (a) the National Health Service
(NHS); (b) the local authority social services department; and $(c)$ the private and voluntary sector. Within this range of provision six specific types of care may be distinguished, and previous reports dealing with various aspects of the study have presented data in relation to them..$^{1-3}$ The present report is concerned mainly with the three types of care that contain the majority of elderly people who require care beyond the confines of an acute episode or who are incapable of coping within the community, even with supporting domiciliary services. Two are provided by the NHS-beds in "geriatric" and "psychiatric" hospitals. The third group are places within "homes for the elderly," which are largely the responsibility of the local authority social services department (a much smaller number of these places are provided by voluntary agencies).

Data were gathered on all people aged 65 and over who were in any form of institutional care in the study area at the time of two cross sectional surveys, three years apart. Linkage of data in these two studies allowed a group of old people to be identified, from the initial population, who had been continuously resident over the entire three year period. The 40 
remaining members of the initial study population were also followed up.

The first survey in December 1976 enumerated a total institutional elderly population of 4490 . The proportions in each type of care were: homes for the elderly (50\%), NHS geriatric beds (17\%), NHS psychiatric beds (16\%), NHS acute beds (8\%), private nursing homes $(7 \%)$, and homes for the handicapped $(2 \%)$. In addition to recording personal and administrative details on each elderly person the survey incorporated an assessment of the extent to which they were capable of undertaking basic activities of daily living (ADL). This assessment of functional capacity, in relation to mobility, urinary incontinence, faecal incontinence, washing/dressing and feeding, was based on a consensus decision by staff immediately concerned with the care of the old person on the descriptive statement in each of the five categories which most nearly described her or him in the one week period before recording. Depending on the setting, caring staff undertaking the assessment had either nursing or social work training or qualifications. Within each category of the assessment points were allocated to each statement and by addition a score for total activities of daily living was obtained in each case. On this scale, the maximum score of 11 indicated high dependency and the minimum score of 0 independence.

The assessment, described in detail elsewhere, ${ }^{12}$ was based on a modified version of a scale originally validated in a population of chronic schizophrenics. ${ }^{4}$ It was later used, and further validated, in a mixed population of schizophrenics and patients with other long standing disorders. ${ }^{5}$ Later, in a population of over 1000 elderly and long stay patients in a psychiatric hospital it was found to be a good predictor of discharge, continuing residence, or death. ${ }^{6}$ Most recently, among elderly people in all types of institutional care increasing incapacity in total ADL score was a strong predictor of increasing mortality. ${ }^{12}$ Moreover, survival figures using the scale in Leicestershire were similar to those obtained at the same time periods for comparable incapacity groupings in an American Study ${ }^{27}$ which had used the Katz index of $\mathrm{ADL}^{8}$ as a measure of incapacity.

Three years later in December 1979, the second survey was conducted on the same range of institutions in the same geographical area. A total of 4678 elderly people were in institutions, and the proportions within the different care settings were similar to those found in $\mathbf{1 9 7 6}$. The data collected were modified or added to in part, but the assessment of functional capacity was retained in an identical form.

Details of the old person's initial assessment were held in the survey office and were not available to staff conducting the second assessment. It was therefore impossible for knowledge of a person's previous status to bias assessment of outcome.

Records from the two surveys were linked manually so that elderly people who were in institutional care on the occasion of both surveys were identified. Searches of draft death returns and records departments of hospitals and the social services department completed the follow up and allowed all members of the inception cohort to be classified into five outcome groups: (a) died (53\%), (b) continuously resident in the same type of care (32\%), (c) transferred to another type of care (almost all to institutions within Leicester) $(5 \%),(d)$ readmitted to institutional care after a spell in the community $(1 \%)$, and (e) living in the community (9\%).

The focus of interest in this report is the change in functional status of those patients (32\% of total) who had been assessed in 1976 and remained continuously resident in the same type of care without interruption over the following three years and were then reassessed. Not included in the follow up of this group were people who were not assessed or on whom data were incomplete at the time of one or other survey. These exclusions represented $3 \%$ of the original cohort and $9 \%$ of the continuously resident group.

In each continuously resident old person level of functional capacity in 1979 was compared with the level in 1976. For each individual activity of daily living (mobility, urinary incontinence, etc), any change to a higher category of incapacity in 1979 (compared with 1976) led to the classification "deteriorated" for that person. Similarly, a lower category of incapacity in activity in 1979 (compared with 1976) meant that the person was classified as "improved." If the same description was made of their status in 1979 as in 1976 then they were classified as "unchanged." Results were expressed as the proportions in each of these three status groups. To facilitate exploration of the effect of other variables - for instance, age and type of institutionon these events, a summary index was constructed for the group of patients whose status had either deteriorated or improved. This index was the "odds in favour of deterioration for those who changed" and was the ratio of the number of patients in the deteriorated category to those in the "improved" category for a particular variable under study.

Data are also presented for change in relation to all activities. The same status categories were used as for the individual aspects of function, but, in this case, change was taken to be a movement in either direction in any of the activities comprising the total activity of daily living score. 
The significance tests involving $\chi^{2}$ described in the text were undertaken using the method of Clayton ${ }^{9}$ for the analysis of ordered categorical data using odds ratio statistics.

The populations of the three types of care with a sizeable long stay element differed in their compositions. Homes for the elderly contained an older population, $44 \%$ were aged 85 and over compared with $35 \%$ for geriatric and $15 \%$ for psychiatric facilities. In contrast, levels of incapacity were higher for the population in geriatric beds: $57 \%$ had a total ADL score of 7 or higher compared with $36 \%$ (psychiatric beds) and 16\% (homes for the elderly).

In order to compare resident patients in different types of care, taking account of variables that significantly influenced deterioration in those who changed, a regression analysis model was applied using the generalised linear interactive modelling system (GLIM) ${ }^{10}$ using the method of Clayton. ${ }^{11}$

A logistic regression analysis was used, the dependent variable being improvement (categorised as either improved or deteriorated). The independent variables considered were age (65-74 years, 75-84, 85 and over), institution (NHS geriatric beds, NHS psychiatric beds, homes for the elderly), duration of stay ( $0-5$ years, over 5 years), total ADL at initial enumeration $(0-2,3-6,7-11)$, and sex.

\section{Results}

Table 1 shows the longitudinal changes in level of incapacity in individual activities of daily living. With the exception of faecal incontinence (where a higher proportion were unchanged but in those whose status did change a greater proportion had deteriorated), broadly similar results were obtained for each activity. Between $58 \%$ and $70 \%$ were unchanged, while change was more often deterioration, as indicated by the proportions deteriorated or improved and the odds in favour of deterioration (between three and four to one).

Table 2 shows changes in all activities. Overall, under a third remained unchanged, over half deteriorated, and under a fifth improved. The degree of change was greater than for individual activities as might be expected since, by including the whole scale, there was clearly more opportunity for change.

Table 1 Change in level of incapacity in each activity of daily living for continuously resident people between 1976 and 1979. (Percentages with numbers shown in parentheses)

\begin{tabular}{|c|c|c|c|c|c|}
\hline \multirow[b]{2}{*}{ Activity of daily living } & \multicolumn{4}{|c|}{ Incapacity status in 1979 compared with 1976} & \multirow{2}{*}{$\begin{array}{l}\text { Odds in favour of } \\
\text { deterioration for } \\
\text { those who changed }\end{array}$} \\
\hline & Improved & Unchanged & Deteriorated & Total $^{*}$ & \\
\hline Mobility & $\begin{array}{c}8 \\
(101)\end{array}$ & $\begin{array}{c}65 \\
(849)\end{array}$ & $\begin{array}{c}27 \\
(356)\end{array}$ & $\begin{array}{c}100 \\
(1306)\end{array}$ & $3 \cdot 5: 1$ \\
\hline Urinary incontinence & $\begin{array}{c}7 \\
(94)\end{array}$ & $\begin{array}{c}63 \\
(824)\end{array}$ & $\begin{array}{c}30 \\
(388)\end{array}$ & $\begin{array}{c}100 \\
(1306)\end{array}$ & $4 \cdot 1: 1$ \\
\hline Faecal incontinence & $\begin{array}{c}2 \\
(31)\end{array}$ & $\begin{array}{c}82 \\
(1066)\end{array}$ & $\begin{array}{c}16 \\
(208)\end{array}$ & $\begin{array}{c}100 \\
(1305)\end{array}$ & $6 \cdot 7: 1$ \\
\hline Washing and dressing & $\begin{array}{c}10 \\
(132)\end{array}$ & $\begin{array}{c}58 \\
(757)\end{array}$ & $\begin{array}{c}32 \\
(416)\end{array}$ & $\begin{array}{c}100 \\
(1305)\end{array}$ & $3 \cdot 2: 1$ \\
\hline Feeding & $\begin{array}{c}7 \\
(87)\end{array}$ & $\begin{array}{c}70 \\
(921)\end{array}$ & $\begin{array}{c}23 \\
(297)\end{array}$ & $\begin{array}{c}100 \\
(1305)\end{array}$ & $3.4: 1$ \\
\hline \multicolumn{6}{|c|}{${ }^{*}$ People not assessed or with incomplete data ( $9 \%$ of the continuously resident group) have been excluded (see text). } \\
\hline \multicolumn{6}{|c|}{$\begin{array}{l}\text { Table } 2 \text { Change in all activities of daily living for continuously resident people between } 1976 \text { and } 1979 \text { by age group. } \\
\text { (Percentages with numbers shown in parentheses) }\end{array}$} \\
\hline \multirow[b]{2}{*}{ Age group in $1976(y)$} & \multicolumn{4}{|c|}{ Status in 1979} & $\begin{array}{l}\text { Odds in favour of } \\
\text { deterioration for }\end{array}$ \\
\hline & Improved & Unchanged & Deteriorated & Total & those who changed \\
\hline $65-74$ & $\begin{array}{l}18 \\
(71)\end{array}$ & $\begin{array}{c}39 \\
(148)\end{array}$ & $\begin{array}{c}43 \\
(166)\end{array}$ & $\begin{array}{l}100 \\
(385)\end{array}$ & $2 \cdot 3: 1$ \\
\hline $75-84$ & $\begin{array}{l}17 \\
(94)\end{array}$ & $\begin{array}{c}29 \\
(158)\end{array}$ & $\begin{array}{c}54 \\
(296)\end{array}$ & $\begin{array}{c}100 \\
(548)\end{array}$ & $3 \cdot 1: 1$ \\
\hline$\geqslant 85$ & $\begin{array}{c}17 \\
(62)\end{array}$ & $\begin{array}{l}20 \\
(74)\end{array}$ & $\begin{array}{c}63 \\
(236)\end{array}$ & $\begin{array}{c}100 \\
(372)\end{array}$ & $3 \cdot 8: 1$ \\
\hline$\geqslant 65$ & $\begin{array}{c}17 \\
(227)\end{array}$ & $\begin{array}{c}29 \\
(380)\end{array}$ & $\begin{array}{c}54 \\
(698)\end{array}$ & $\begin{array}{c}100 \\
(1305)\end{array}$ & $3 \cdot 1: 1$ \\
\hline
\end{tabular}

*People not assessed or with incomplete data ( $9 \%$ of the continuously resident group) have been excluded (see text).

Table 2 Change in all activities of daily living for continuously resident people between 1976 and 1979 by age group. (Percentages with numbers shown in parentheses) 
Nevertheless, the nature of the change with a three to one deterioration among those elderly people whose status had changed was of a similar order of magnitude for all activities as it had been for individual activities. A greater degree of deterioration occurred with increasing age (table 2). This age related trend was statistically significant at the $2 \%$ level $\left(\chi_{d f}^{2}=6 \cdot 14 ; p<0.02\right)$. When it was examined for the two sexes separately, however, a significantly greater level of deterioration with age persisted in women $\left(\chi_{d f}^{2}=7.47 ; \mathrm{p}<0.01\right)$ but not in men.

Those old people who had been resident for longer periods before initial assessment changed their status and deteriorated less over the succeeding three years than their shorter stay counterparts (table 3 ). This difference between the different duration of stay groups was significant at the $1 \%$ level $\left(\chi^{2}{ }_{d f}=6.66\right.$; $\mathrm{p}<0 \cdot 01)$. The main difference, however, was between the group who had already been resident for five years or longer (greater stability and less deterioration) and those whose duration of stay was less than five years (greater change and more people who had deteriorated). Most of the group who had been resident for more than five years before initial assessment were in psychiatric hospitals.

Table 4 examines change in the three longer stay care settings. The greatest change in functional status over three years occurred in geriatric hospital patients-only $23 \%$ were unchanged. Higher proportions remained unchanged among the populations in psychiatric beds (28\%) and homes for the elderly $(30 \%)$. Similarly, for the elderly people whose status had changed, greatest deterioration occurred in the geriatric hospital population and least in the psychiatric hospital patients.

As described in the methods section, however, populations in the three types of care differed in terms of age and sex structure, durations of stay, and initial levels of incapacity, all of which significantly affected change over the three year period. In order to compare the extent of deterioration among individual people in these three settings whose status had changed and who were similar with respect to these variables, a regression analysis model was applied (as described in the methods section).

A final model that included level of incapacity, type of institution, age, sex, and duration of stay gave

Table 3 Change in overall incapacity (percentages) among people continuously resident between 1976 and 1979 by duration of stay before initial assessment

\begin{tabular}{|c|c|c|c|c|c|}
\hline \multirow[b]{2}{*}{ Duration of stay before $1976(y)$} & \multicolumn{4}{|c|}{ Status in 1979} & \multirow{2}{*}{$\begin{array}{l}\text { Odds in favour } \\
\text { deterioration for } \\
\text { those who changed }\end{array}$} \\
\hline & Improved & Unchanged & Deteriorated & Total & \\
\hline$<1$ & 17 & 25 & 58 & 100 & $3 \cdot 4: 1$ \\
\hline $1-2$ & 14 & 26 & 60 & 100 & $4 \cdot 2: 1$ \\
\hline $2-5$ & 15 & 30 & 54 & 100 & $3 \cdot 6: 1$ \\
\hline $5-10$ & 22 & 31 & 48 & 100 & $2 \cdot 2: 1$ \\
\hline$>10$ & 21 & 35 & 44 & 100 & $2 \cdot 1: 1$ \\
\hline All durations of stay & 17 & 29 & 54 & 100 & $3 \cdot 1: 1$ \\
\hline No $(100 \%)=$ & (227) & $(380)$ & (698) & $(1305)$ & \\
\hline
\end{tabular}

Table 4 Change in all activities of daily living for elderly people continuously resident in various types of care. (Percentages with numbers shown in parentheses)

\begin{tabular}{|c|c|c|c|c|c|}
\hline \multirow[b]{2}{*}{ Type of care in 1976} & \multicolumn{4}{|c|}{ Status in 1979} & \multirow{2}{*}{$\begin{array}{l}\text { Odds in favour } \\
\text { deterioration for } \\
\text { those who changed }\end{array}$} \\
\hline & Improved & Unchanged & Deteriorated & Total & \\
\hline NHS geriatric beds & $\begin{array}{c}14 \\
(11)\end{array}$ & $\begin{array}{c}23 \\
(18)\end{array}$ & $\begin{array}{c}63 \\
(48)\end{array}$ & $\begin{array}{l}100 \\
(77)\end{array}$ & $4 \cdot 4: 1$ \\
\hline NHS psychiatric beds & $\begin{array}{l}21 \\
(65)\end{array}$ & $\begin{array}{l}28 \\
(90)\end{array}$ & $\begin{array}{c}51 \\
(162)\end{array}$ & $\begin{array}{l}100 \\
(317)\end{array}$ & $2 \cdot 5: 1$ \\
\hline Homes for the elderly & $\begin{array}{c}17 \\
(138)\end{array}$ & $\begin{array}{c}30 \\
(246)\end{array}$ & $\begin{array}{c}53 \\
(435)\end{array}$ & $\begin{array}{l}100 \\
(819)\end{array}$ & $3 \cdot 2: 1$ \\
\hline Total & $\begin{array}{c}18 \\
(226)\end{array}$ & $\begin{array}{c}28 \\
(365)\end{array}$ & $\begin{array}{c}54 \\
(686)\end{array}$ & $\begin{array}{c}100 \\
(1277)^{*}\end{array}$ & $3 \cdot 0: 1$ \\
\hline
\end{tabular}

* Total differs from other tables because 28 people resident in homes for the handicapped and private nursing homes have been excluded. 
a reasonable fit, indicating that the differences were largely explicable on the basis of these factors. After adjustment for the other factors, a series of comparisons could then be made between the extent of deterioration in the three types of care. Details of these comparisons are shown in the three equations below. The ratio of the odds of deterioration (after adjustment) in two types of care is shown together with its $95 \%$ confidence limits (shown in parentheses).

After adjustment, there was no significant difference (at the 5\% level) in deterioration between patients in NHS geriatric and psychiatric beds (equation (a)). Nevertheless, even after adjustment for other factors affecting deterioration, there was a significantly greater degree of deterioration (at the $5 \%$ level) among patients in both types of hospital settings than for their counterparts in homes for the elderly (equations $(b)$ and $(c)$ ):

(a) Odds of deterioration in geriatric hospital patients

Odds of deterioration in psychiatric hospital patients

$$
1 \cdot 40
$$

$=$

(b) Odds of deterioration in geriatric hospital patients Odds of deterioration in residents of homes for the elderly $=$

(c) Odds of deterioration in psychiatric hospital patients $2 \cdot 68$ Odds of deterioration in residents of homes for the elderly

\section{Discussion}

Many of the studies which have examined changes over time in functional capacity using such standardised indices in the institutional setting are attributable to workers in the United States studying disability in chronic disease.

One study followed up 159 patients with stroke over a period of six years with six monthly reassessment. ${ }^{12}$ The authors were principally concerned with return to prestroke levels of independence. The assessments, however, were based on activities of daily living as well as level of mobility (as a separate study). The finding that young patients recovered walking and ADL levels more frequently than older patients was to be expected and agrees with the relation between age and increased deterioration in functional capacity found in the present study. Further comparisons are made difficult by the fact that the former study deliberately selected patients who in the main had been free of any incapacity in mobility or activities of daily living before admission.

This is a perfectly valid approach when looked at in the context of a single diagnostic category-for instance, people with first strokes ${ }^{14}$ when the aim of the study is to examine improvement or lack of improvement in connection with certain variables or rehabilitative procedures. Unfortunately, many of the relatively few available data have been limited in just this way to particular diagnoses, such as stroke ${ }^{13-15}$ or fractured hip. ${ }^{16-18}$

A recent cohort study conducted in Massachusetts and reported by Branch and Jette has provided valuable data on factors which may increase the risk of long term care institutionalisation in a community sample of the elderly. ${ }^{19}$ The author's use of a multiple regression analysis to examine the predictive power of 19 independent variables indicated that old people who were very elderly, living alone, used aids to facilitate walking, were mentally disorientated, or had help to perform instrumental activities of daily living had a greater likelihood of admission to a long term care institution over the following six years.

The longitudinal element of the present study is concerned with the course of those patients who have already entered longer term institutional care. This has its limitations. The most important is that the old people studied here could not be regarded as representing all those in institutional care. Excluded were elderly people who had died and those who had been discharged. The effect of selection here will have been to remove people at the two ends of the range of severity. People who died are likely to have deteriorated to a greater extent than survivors, and people who improved either spontaneously or as a result of treatment or rehabilitation are likely to have been discharged, although this latter group was small. Continuously resident survivors (about a third of the original population), however, represent a substantial group who are of importance to long stay institutions, where transfer or discharge is not a common or easy event. Given these limitations, the finding was that staff in geriatric hospitals, psychiatric hospitals, and homes for the elderly faced an increasing burden of incapacity from patients and residents who remained with them over a period of several years.

Greater change and hence greater deterioration, as would be expected, occurred with increasing age. It is not possible to say at which point over the three year period change took place and whether it was gradual or sudden. A person highly incapacitated in 1976 as a result of acute illness, for example, but who responded to treatment relatively quickly and was placed in long term care for reasons such as 
advancing age or poor social circumstances would show up as improved in 1979. This would clearly be a different situation from someone who had gradually changed their status over the three year period. Much of the acute illness effect would be reduced by the exclusion of patients in acute hospitals where long stay is infrequent and, to a much lesser extent, by exclusion of the small number of patients who were transferred from acute hospitals to longer stay facilities.

Further light is thrown on the stability of the index by the data for duration of stay. Less change and less deterioration occurred in people with longer durations of stay before initial assessment. Those who had been resident for a relatively long time before assessment (five years or more) changed least and deteriorated least. This longer stay group mainly comprised psychiatric patients who were admitted at younger ages and had grown old within the institution. The fact that the level of deterioration in people with durations of stay under a year was similar to or less than the other groups with durations of stay under five years, suggests that whereas change cannot be assumed to be uniform over time, the results of the present study are unlikely to be heavily influenced by changes in the early period which have then remained stable for the rest of it. The adverse effect of long term care in an institutional setting on the individual's self esteem and degree of self determination has been widely aired in sociological publications emanating from the writing of Goffman. ${ }^{20}$ What has not been established is the extent to which various institutional regimens or environments affect outcome variables such as death or level of incapacity. One approach, which has been used to explore the impact of environment on outcome, is through so called "relocation" studies of the elderly in which the course of elderly populations after movement (from community to institution, between institutions, or within sections of the same institution) have been compared with "non-relocated" groups. ${ }^{21} 22$ In some studies it is difficult to eliminate unequivocally selection bias arising from a transferred group of patients differing from a remaining group in terms of important variables that affect outcome. ${ }^{23}$ Even when the study population has comprised elderly residents relocated because of the closure of an institution, the use of historical rather than concurrent controls is a potential source of spurious conclusions. ${ }^{24} 25$

Perhaps the greatest drawback of this substantial body of data is the difficulty in designing studies to unravel the potential impacts of the several dimensions of the relocation process and separating its effects from those of institutionalisation.
The present study cannot draw inferences on the adverse effects of institutional settings per se because it lacks a comparable group of elderly people outside the institutional system. Such a group would be necessary to separate changes from the aging process over time.

Nevertheless, in the three important types of care provided largely by statutory agencies and with large numbers of long stay patients and residents there were differences. The greatest degree of change in functional capacity took place in geriatric hospital patients in whom deterioration was also greatest (almost four and a half times the number who improved).

The use of regression analysis to adjust for differences in some variables which significantly affected change has shown that the degree of deterioration was similar for "comparable" individuals in geriatric and psychiatric hospitals, but significantly greater in both cases than for "similar" old people in homes for the elderly. Thus once the effect of the "graduate" psychiatric patients has been excluded, it seems that people who are already elderly at the time of admission either to geriatric or psychiatric care, and then continuously resident for a period of years, undergo similar change in functional capacity.

It is impossible to exclude fully a confounding effect. Indeed, it may seem more plausible that the matching of the two groups of elderly people has failed to take account of another important extraneous characteristic that both influences change in functional capacity and is more common in hospital patients than residents of homes for the elderly. The most logical candidate would seem to be a diagnostic effect-would the presence of incapacity arising from a specific disease process such as stroke, induce greater and more rapid deterioration than the same level of incapacity (judged on ADL) arising from increasing, non-specific frailty of old age? If another factor was influencing deterioration in function in this way, it might be expected to be manifest in terms of mortality. This hypothesis was not substantiated by the mortality component of the present study ${ }^{26}$ : most of the significant differences in survival among elderly people in different types of care disappeared when differences in functional capacity and age were taken into consideration, a finding consistent with another study of the institutionalised elderly (albeit a smaller and more selected sample) in the British context. ${ }^{27}$ It seems unlikely that many disease processes (in the present study) did "over-ride" the prognostic effect of level of functional capacity. 
Moreover, analysis of place of death data showed that most deaths occurred within the type of institution of enumeration, ${ }^{28}$ thereby making unlikely a major selection bias resulting from transfer, out, of residents of homes for the elderly immediately before death.

Although the present study cannot conclude unequivocally that the apparently greater extent of deterioration among elderly people in the long stay NHS settings compared with their counterparts in residential homes who survived, were continuously resident, and changed in status was due to the adverse effects of NHS institutional regimens, it would seem that this is an important area for further study. It is one that could contribute to decisions about the type of long term care provided for elderly people no longer capable of living in the community even with adequate supporting services.

I am grateful to all nursing and care staff in NHS and social services premises in Leicestershire who assisted with data collection and to the following individuals who acted as fieldwork co-ordinators: Professor S Brandon, Professor Michael Clarke, Dr M G Clarke, Dr R L Palmer, Mrs S Clarke, Mr M Baxandall, Dr A Williams, Mrs K Dodd, Dr W D Revill, Dr R W Kind, Miss A Odell, Mr J Dykes, Dr M Castleden, Mr J Henson, and Mr S Cardy.

I also thank David Clayton and Carol Jagger for statistical advice and Mr John Woods for help with computing.

Leicestershire Health Authority provided financial support.

\section{References}

${ }^{1}$ Clarke M, Hughes AO, Dodd KJ, et al. The elderly in residential care: patterns of disability. Health Trends 1979; 11: 17-20.

${ }^{2}$ Donaldson LJ, Clayton DG, Clarke M. The elderly in residential care: mortality in relation to functional capacity. J Epidemiol Community Health 1980; 34: 96-101.

${ }^{3}$ Donaldson LJ, Clarke M, Palmer RL. Institutional care for the elderly: the impact and implications of the aging population. Health Trends 1983; 15: 58-61.

4 Wing JK, Brown GW. Institutionalism and schizophrenia: a comparative study of three hospitals 1960-1968. Cambridge: Cambridge University Press, 1970.

${ }^{5}$ Philip AE, McKechnie AA. The assessment of long-stay psychiatric patients. Social Psychiatry 1969; 4: 66-81.

${ }^{6}$ Clarke M, Waller J, Webster $B$. The assessment and progress of long-stay and elderly psychiatric patients: the predictive validity of a ward behaviour questionnaire. Br J Psychiatry 1975; 127: 149-56.
${ }^{7}$ Jones EW, Densen PM, McNitt BJ. Assessing the quality of long-term care. Research summary series. Maryland: National Centre for Health Service Research, 1978.

${ }^{8}$ Katz S, Ford AB, Moskowitz RW, Jackson BA, Jaffe MA. Studies of illness in the aged: the index of ADL, a standardised measure of biological and psychosocial function. JAMA 1963; 185: 914-9.

${ }^{9}$ Clayton DG. Some odds ratio statistics for the analysis of ordered categorical data. Biometrika 1974; 61: 525-31.

${ }^{10}$ Royal Statistical Society. The GLIM system-generalised linear interactive modelling manual. Oxford: Numerical Algorithms Group, 1978.

${ }^{11}$ Clayton DG. The analysis of prospective studies of disease aetiology. Communications in Statistics 1982; 11: 2129-58.

${ }^{12}$ Katz S, Ford AB, Chinn AB, Newill VA. Prognosis after strokes: II Long-term course of 159 patients with stroke. Medicine 1966; 45: 236-46.

${ }^{13}$ Moskowitz E, Lightbody FEH, Freitag NS. Long-term follow up of the post-stroke patient. Arch Phys Med Rehabil 1971; 53: 167-72.

${ }^{14}$ Lehman JF, De Lateur BJ, Fowler RS, et al. Stroke: does rehabilitation affect outcome? Arch Phys Med Rehabil 1975; 56: 375-82.

${ }^{15}$ Granger CV, Sherwood CC, Greer DS. Functional status measures in a comprehensive stroke care programme. Arch Phys Med Rehabil 1977; 58: 555-61.

${ }^{16}$ Staff of the Benjamin Rose Hospital. Studies of illness in aged persons II: a new classification of functional status? in activities of daily living.J Chronic Dis 1959; 9: 55-62.

${ }^{17}$ Katz S, Ford AB, Heiple KG, Newill VA. Studies of illness in the aged: recovery after fracture of the hip. $J$ Gerontol 1964; 19: 285-93.

${ }^{18}$ Katz S, Heiple KG, Downs TD, Ford AB, Scott CP. Long-term course of 147 patients with fracture of the hip. Surg Gynecol Obstet 1967; 124: 1219-30.

${ }^{19}$ Branch LG, Jette AM. A prospective study of long-term care institutionalisation among the aged. Am J Public Health 1982; 72: 1373-9.

${ }^{20}$ Goffman E. Asylums: Essays on the social situation of mental patients and other inmates. Chicago: Aldine? Publishing Co, 1961.

${ }^{21}$ Lieberman MA. Institutionalisation of the aged: effects on behaviour. J Gerontol 1969; 24: 330-40.

${ }^{22}$ Schulz R, Brenner G. Relocation of the aged: a review and theoretical analysis. J Gerontol 1977; 32: 323-33.

${ }^{23}$ Markson E, Cumming JH. A strategy of necessary mass transfer and its impact on patient mortality. J Gerontol 1974; 29: 315-21.

${ }^{24}$ Aldrich CK, Mendkoff E. Relocation of the aged and disabled: a mortality study. J Am Geriatr Soc 1963; 11: 185-94.

${ }^{25}$ Gutman GM, Herbert CP. Mortality rates among relocated extended-care patients. J Gerontol 1976; 31: 352-7.

${ }^{26}$ Donaldson LJ, Jagger C. Survival and functional capacity: three year follow up of an elderly population in hospitals and homes. J Epidemiol Community Health 1983; 37: 176-9.

${ }^{27}$ Gilleard CJ, Pattie AH. The effect of location on the elderly mentally infirm: relationship to mortality and behavioural deterioration. Age Ageing 1978; 7: 1-6.

${ }^{28}$ Donaldson LJ. Studies of the elderly in hospital and homes. Leicester: University of Leicester, 1982. (Dissertation for the degree of Doctor of Medicine.) 